\title{
Projecting Extreme Changes in Summer Rainfall in South America by the Middle of the 21st Century
}

\author{
Paula Andrea M. Fonseca ${ }^{1}$, José Augusto P. Veiga ${ }^{2 *}$, Francis Wagner S. Correia ${ }^{2}$, \\ Adriane L. Brito², Mônica R. Queiroz ${ }^{3}$, André A. Lyra ${ }^{4}$, Sin Chan Chou ${ }^{4}$ \\ ${ }^{1}$ Post Graduation Program in Climate and Environment/National Institute for Amazonia Research (INPA) and \\ Amazonas State University, Manaus, Brazil \\ ${ }^{2}$ Institute of Technology, Amazonas State University, Manaus, Brazil \\ ${ }^{3}$ UNINORTE Laureate International Universities, Manaus, Brazil \\ ${ }^{4}$ National Institute for Space Research (INPE), Cachoeira Paulista, Brazil \\ Email: *veiga.uea@gmail.com
}

Received 10 August 2014; revised 20 September 2014; accepted 25 October 2014

Copyright (C) 2014 by authors and Scientific Research Publishing Inc.

This work is licensed under the Creative Commons Attribution International License (CC BY).

http://creativecommons.org/licenses/by/4.0/

(c) (i) Open Access

\begin{abstract}
Extreme rainfall events can be considered a natural manifestation of the environment in which they are embedded and foreknowledge about their future behavior is very important, especially for decision makers. In this context, we aimed to explore the future behavior of extreme rainfall intensity through numerical simulations with the ETA model. The model was forced with a scenario of high greenhouse gas emissions for the middle of the $21^{\text {st }}$ Century as described for A1B emission scenario. We detailed the main changes in accumulated rainfall produced by heavy events, very heavy events and rare events over a broad area of South America with a focus on the tropical sector. The methodology applied here is capable of separating extreme events and establishing the quantity of rainfall yielded by them. We have found that in the near future (2041-2050) rare events will tend to increase over the Amazon basin, followed by reductions in heavy and very heavy events. Conversely, heavy, very heavy and rare events are expected to decline over northeast Brazil. Furthermore, increases were found for heavy, very heavy and rare events over southern Brazil.
\end{abstract}

\section{Keywords}

Climate Change, Extreme Events, Amazon, South America

\footnotetext{
${ }^{*}$ Corresponding author.
}

How to cite this paper: Fonseca, P.A.M., Veiga, J.A.P., Correia, F.W.S., Brito, A.L., Queiroz, M.R., Lyra, A.A. and Chou, S.C. (2014) Projecting Extreme Changes in Summer Rainfall in South America by the Middle of the 21st Century. Atmospheric and Climate Sciences, 4, 743-756. http://dx.doi.org/10.4236/acs.2014.44067 


\section{Introduction}

Extreme rainfall events can impose major impacts on the local environment, affecting the ecology, human life, buildings, agriculture and economy. These impacts can be enhanced depending on local vulnerability and the severity of the rainfall event. It is also recognized that one of the main consequences of an accelerated warming climate, especially that component related to human activities, will be an increase in the intensity and frequency of rainfall severity [1]-[7]. Such an increase is a response to the enhancement of the atmosphere's moisture content [8]. Knowledge about future changes in the intensity and frequency of heavy rainfall is of great importance to decision makers, who can use such information to minimize the environmental and social impacts through public policy actions.

According to [9] developing countries are not adapting to climate change consequences yet. Lack of awareness and understanding is one of the reasons that prevent these countries to make better decisions, and properly deal with climate extremes due to natural variability or due to climate change. It is expected that the analysis presented here can contribute to improving this reality.

Extreme events induced by climate change represent a serious threat to food production worldwide [10]. Missing long-term and trustworthy data series prejudice or limit the understanding of the rainfall regime's behavior and extreme distribution especially in Amazonia. The information, most of the times, is not considered while choosing the crop to be planted which tends to facilitate try and errors policies that should be avoided when it comes to irrigation systems implementations [11], for example, once it wastes scarce resources. A solution for missing data could be time series model forecast such as discussed in [12]. As shown in [13] a minimum of 10 years of rainfall data can produce a good data series with $\mathrm{R}^{2}$ up to 0.70 for humid regions.

The Amazon basin and neighboring areas have undergone continuous significant changes in their hydrological regime in the last decade. For example, in 2005 the southwestern Amazon basin was subjected to one of the most severe droughts of the last 100 years. According to [14] the drought condition resulted from an extended dry season as a consequence of reduced rainfall and significant reduction in moisture transport from the north Atlantic during the Austral summer season. Five years later, the Amazon region again faced intense drought conditions. The extreme 2010 drought was due to circulation changes tied to an anomalous warming pattern in the tropical North Atlantic, which forced the ITCZ to shift anomalously northward from its standard climatological position [15]. The authors observed that the reduction in rainfall was more extensive during the dry than wet season, and affirmed that the slight increase in the length of the dry season in the Amazon basin was strongly related to SST warming in the North Atlantic Ocean. During 2009 the Amazon basin experienced heavy flooding conditions that impacted the livelihoods of the floodplain population [16]. According to [16], the combination of a premature onset of the rainy season in the northern and northwestern Amazon that enhanced moisture transport from the tropical North Atlantic, together with an unusually intense Chaco low and an anomalous southward ITCZ position, was responsible for the flooding. In 2012 the Amazon basin again experienced unprecedented flood conditions, which according to [17] were provoked by an early excessive wet season over the north of the basin. [18] conducted a moisture flux analysis for the Amazon basin to explore its role in explaining the flood of 2012. According to the authors the prolonged cold phase from the middle of 2011 till May 2012, a slightly anomalous warm tropical North Atlantic followed by a cooler than normal South Atlantic and a moisture flux convergence 38\% higher than normal caused excessive rainfall in the Amazon basin and consequently influenced the 2012 Amazon flood. [19] classified the most recently Southwestern Amazon flooding, occurred in the first semester of 2014, as an extreme event and highlighted that even considering the actual climate projections, that suggest the increase in frequency to this type of extreme, it is not possible yet to confirm that it was caused by the global warming. Furthermore, the construction of the Madeira River's dam enhanced the impacts of the meteorological event in Bolivia, Peru and in Brazil [20]. [21] assessed rainfall trends over the last 70 - 80 years in the Amazon basin from 18 sets of homogeneous station data. The results indicated no significant rainfall trend in the whole Amazon region, either seasonally or annually. Moreover, they found a decreasing trend in the western Amazon where the forest is still preserved, which contradicted numerical modeling studies [22]. In addition, an increasing rainfall trend was still observed in the eastern portion where the forest has been depleted. Results based on modeling experiments have suggested possible changes in the Amazon's precipitation pattern [22]-[25] as a result of both changes in land use and atmospheric composition. The ETA model was forced with boundary and initial conditions from HadCM3 in [26] and the study affirmed the increased intensity of either drought or flood in a warmer climate over the Amazon, depending on the statistical indices applied. For example, 
based on the CDD index the Amazon basin will achieve a pattern where severe drought is more likely and, according to the R95p index, the Amazon will experience more cases of intense flooding in the near future. Based on climate model projections, [27] observed percentage declines in pluviometric precipitation over the Amazon as the temperature increases, especially from the 2040s onward. [28] assert that in the near future extreme rainfall events will tend to be more hostile, with more frequent drought and flood regimes.

[29] presented an analysis of the actual status of area equipped for irrigation worldwide for the period of 1962 and 2011 using data from the FAO Data Base. Eight indexes were calculated and two other were derived from the previous ones. Surprisingly it was found that $46 \%$ of the cultivated areas in the world are not adequate to rainfed agriculture due to climate change or meteorological aspects. And northeast of Brazil has vast areas with tops $500 \mathrm{~mm} \cdot \mathrm{yr}^{-1}$ of precipitation that can be reduced as a consequence of the global warming. It demands that the government should improve the actual water management policies specially those ones related to agriculture. The Southeast region of Brazil could take important advantages of these policies' improvements since it has been facing severe droughts as the one that is affecting the Cantareira System.

To deal with hostile environments for farming, irrigation techniques could represent an opportunity not only to ensure food production but also to increase and diversify it. Also it can provide life quality for rural population and diminish migration to big cities. The more populated the city is the greater are demands for potable water and urbanization which increases the pressure to occupy areas that are not adequate for living [30] (e.g. floodplains in Amazon). Projection of the indexes calculated in [29] was presented for Americas in [31] and it was found that in South America, which today has $12.6 \%$ of area equipped for irrigation, it will present $18.4 \%$ by 2060 considering that variation in the index would have the same slope it had during 1962-2011. This value will be equal to North America that today presents $14.2 \%$ and remains in the top of the list for Americas.

As we noted, few details are known about the anticipated changes in the intensity and frequency of extreme rainfall over the Amazon basin and neighboring areas, especially in the case of rare events. In this context, this work aims to assess future changes in extreme rainfall in South America (SA) using the regional ETA model driven by the UK Met Office (UKMO) Hadley Centre HadCM3 global model and GHG concentration scenarios of current and potential future conditions.

\section{Methodology}

\subsection{Model Descriptions}

The numerical simulations used here were performed with the limited area ETA model in which the HadCM3 coupled model boundary conditions were nested. In the next sections a brief description of both models will be provided. Further information can be found in [32].

\subsubsection{The HadCM3 Global Model}

The numerical experiments were performed with the ETA model forced from initial and boundary conditions generated by the coupled global model HadCM3 [32] [33]. This version of the Hadley Centre coupled ocean atmospheric model presents improvements from its previous version, with no need of flux adjustment to correct the climate drift usually observed in the resulting data [34]. In addition it has a realistic present day mean climate. The HadCM3 model is a version of the UKMO forecast and climate models and has a spatial resolution of $2.5^{\circ} \times 3.75^{\circ}$ and 19 vertical levels [34]. The main improvements in HadAM3 (the atmospheric module of HadCM3) were the inclusion of the radiative effects of aerosols and trace gases and the effects of $\mathrm{CO}_{2}$ on evaporation at the land surface [35].

As described in [32], the initial and boundary conditions provided by HadCM3 came from a perturbed physical ensemble (PPE), which was done by running the model several times and testing its different parameterization schemes to study the uncertainties associated with the process represented in the model or its physical parameterization. However, the design of these experiments included quantification concerning the projection of climate change too. Summarizing the process, specific variables were carefully observed during the experiments and their range was identified. This information was then used to pick 16 model variants that actually representted the uncertainties concerning the model's parameterization. These correspond to the PPE mentioned above. Following this step, these 16 configuration variants were forced with the SRES A1B emission scenario concentrations through the 21st century (see [36]). Authors [32] highlighted that even with the $\mathrm{CO}_{2}$ concentration fixed at $330 \mathrm{ppm}$ the fact that the experiments were run using different configuration was enough to produce different 
results in the climate change projections. At the end, three members were selected that displayed high, medium and low sensitivity in terms of global mean temperature response. Among these three members, the unperturbed member was used to provide the control experimental data, which is the 1961-1990 experiment. The high sensitivity member provided the boundary conditions for driving the ETA regional model for either present-day or future climate [32].

\subsubsection{The ETA Regional Model}

The ETA regional climate model (RCM) is a grid-point model based on the eta vertical coordinate scheme [37] obtained through the following formula:

$$
\eta=\left(\frac{p-p_{T}}{p_{s f c}-p_{T}}\right)\left[\frac{p_{\text {ref }}\left(z_{s f c}\right)-p_{T}}{p_{\text {ref }}(0)-p_{T}}\right]
$$

Equation (1): Formula used to obtain the eta vertical coordinate.

According to the author [37],

$\eta$ refers to the ETA coordinate to be obtained from the parameters bellow;

$p_{T}$ refers to the pressure over the top domain (lower value isobar);

$p_{s f c}$ and $z_{s f c}$ correspond to the pressure and elevation, respectively, of the lower limit of the model, i.e., the surface;

$p_{\text {ref }}$ denotes the status of the pressure reference, which is a function of the distance above sea level (standard atmosphere considered).

The first term in the equation corresponds to the standard sigma coordinate, while the second is a function of $x, y$ and is responsible for converting the sigma coordinate into an eta coordinate.

Using the downscaling technique [32] improved the coarse resolution of a climate projection data provided by the HadCM3, since the method enables mesoscale processes to be solved and allowed other surface properties such as topography or land use to be included in the simulations, which improved the results' quality. For this study a dynamical downscaling was applied, nesting a RCM into the GCM’s conditions.

Modifications were made to the ETA model to adapt it for climate change runs by using Sea Surface Temperature SST data derived from monthly means from HadCM3. The model updates daily SST through linear interpolation. The major modification is the 360-day calendar year, which is necessary in order to use lateral boundary conditions from HadCM3 [32].

The experiments analyzed here used the cumulus parameterization scheme from the Betts-Miller-Janjié scheme (see details in [38]) and the Zhao cloud microphysics scheme reported by [39]. The land surface scheme was provided by [40] and [41]. The vegetation data were provided by the PROVEG project [42]. The Geophysical Fluid Dynamic Laboratory has a radiation scheme package that includes the shortwave radiation scheme from [43] and the long-wave radiation scheme from [44] both used in the numeric experiments.

\subsection{Experimental Design and Scenarios}

\section{Numerical Integrations}

Experiments for three different time slices were performed, 1960-1990, 2010-2040, 2070-2100, for low and high sensitivity and for an unperturbed scenario. Unperturbed conditions represents the current scenario (present day climate) of greenhouse gas (GHG) emissions obtained from the atmospheric model HadCM3 was considered and the $\mathrm{CO}_{2}$ concentration was set to a constant value of $330 \mathrm{ppm}$ [32]. In the experiments on future climate the emission scenario SRES A1B obtained from the atmospheric model HadCM3 was considered. The ETA regional model nested in these lateral boundary conditions was run over 2010-2040 and 2070-2100 to simulate possible future changes. The ETA model was set up for a $40 \mathrm{~km}$ horizontal resolution and 38 vertical layers. In this paper, we only considered one present day climate (1981-1990) decade and a future climate (2041-2050) decade. All the details exposed here and further about the experiments which generated these dataset can be obtained in [32].

\subsection{Method of Identifying and Classifying Extreme Events}

Following the data generation phase performed by the ETA model, the $R X 5$ day method documented and used 
by [45]-[47] and an adapted form proposed by [48] was applied to identify and classify the extreme rainfall events.

The data series available were analyzed in subsets of 5 days, and in each subset the highest value of daily rain was targeted. Once it was found, the first day of this subset was removed, the next value following the subset was added, and this new 5-day subset was analyzed. This process was continued until the final 5-day subset was reached. Considering that each decade has a set with 900 days, exactly 896 5-day subsets can be analyzed, so exactly this number of precipitation maxima was found. From this resulting subset an average was calculated, and it was considered a parameter to isolate from the original data series those values that are equal to or higher than the maximum average for each grid point. Thus, the events that comprise all the precipitation extremes are those that attend the former condition.

The second step was to classify the intensity of an extreme rainfall event. It was done by using the maximum average, also called the maximum climatology, which was calculated previously as well as its standard deviation.

Heavy events will be those that fulfill two conditions: they should be equal to or greater than the maximum climatology, and less than the maximum climatology plus its standard deviation. Thereafter, very heavy events will be those attending two other conditions; namely, they should be equal to or greater than the maximum climatology plus its standard deviation, and less than the maximum climatology plus twice its standard deviation. Finally, rare events will be those equal to or greater than the maximum climatology plus twice its standard deviation.

The choice of the extreme rainfall category followed [49]. However, here the extreme events' threshold was based on the regional climatology of rainfall, avoiding the use of a unique rainfall value.

\section{Results}

As can be seen in Figure 1, four different areas in Brazil will be carefully analyzed, Northeast, Amazon, Amazonas State and Southern regions. An integrated analysis of each of them is presented in this section.

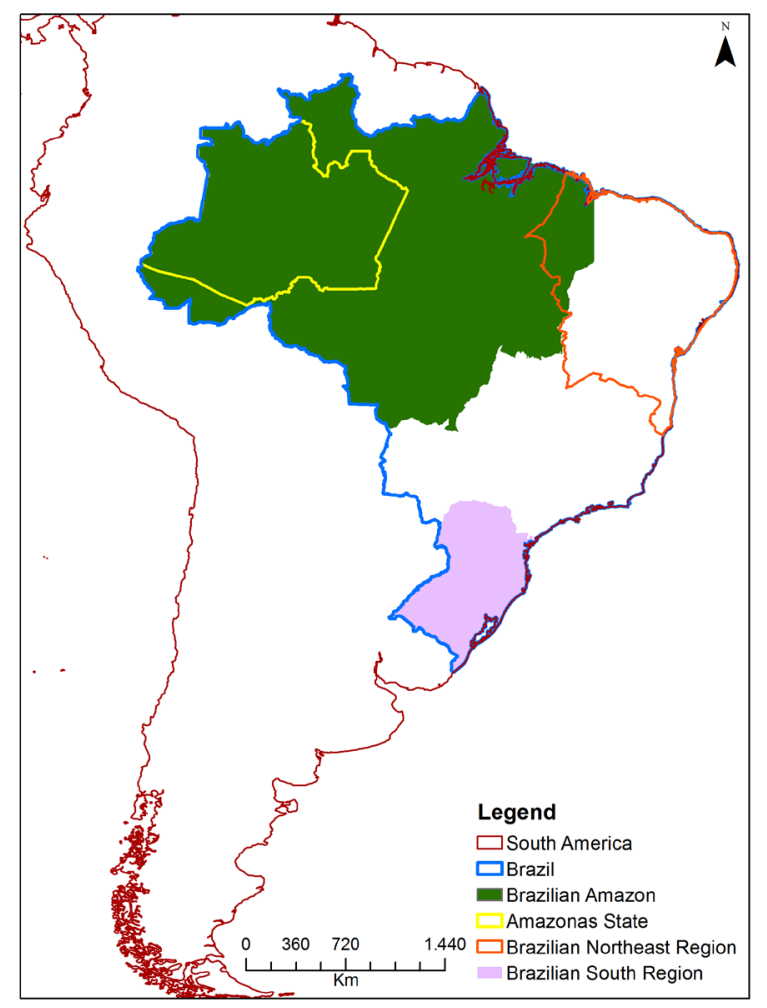

Figure 1. South America boundaries. Although ETA projections were performed for the entire continent, here it is analyzed Northeast, Amazon and South Brazilian regions and Amazonas State. 
A good performance of model simulations relative to the observed data is a key factor in assessing the robustness of the results' confidence. Although the performance of ETA has already been presented in [32], Figure 2(a) and Figure 2(b) present the climatology of the accumulated precipitation for JFM from CRU data (a) and the ETA model (b). The BIAS is depicted in Figure 2(c). As can be seen from Figure 2(a) and Figure 2(b) the simulation of the accumulated rainfall is in good agreement with the observed data, showing the good performance of the ETA model. In addition, the model succeeded in replicating the maximum accumulated rainfall over the Amazon region as well as the small quantities of rainfall over northeast Brazil. The main differences occur over the central part of the Amazon basin, the extreme north of Pará State and southeast of Brazil (Figure 2(c)). Similar results were found in [32]; however, small differences still persist due to different time periods being used in both studies.

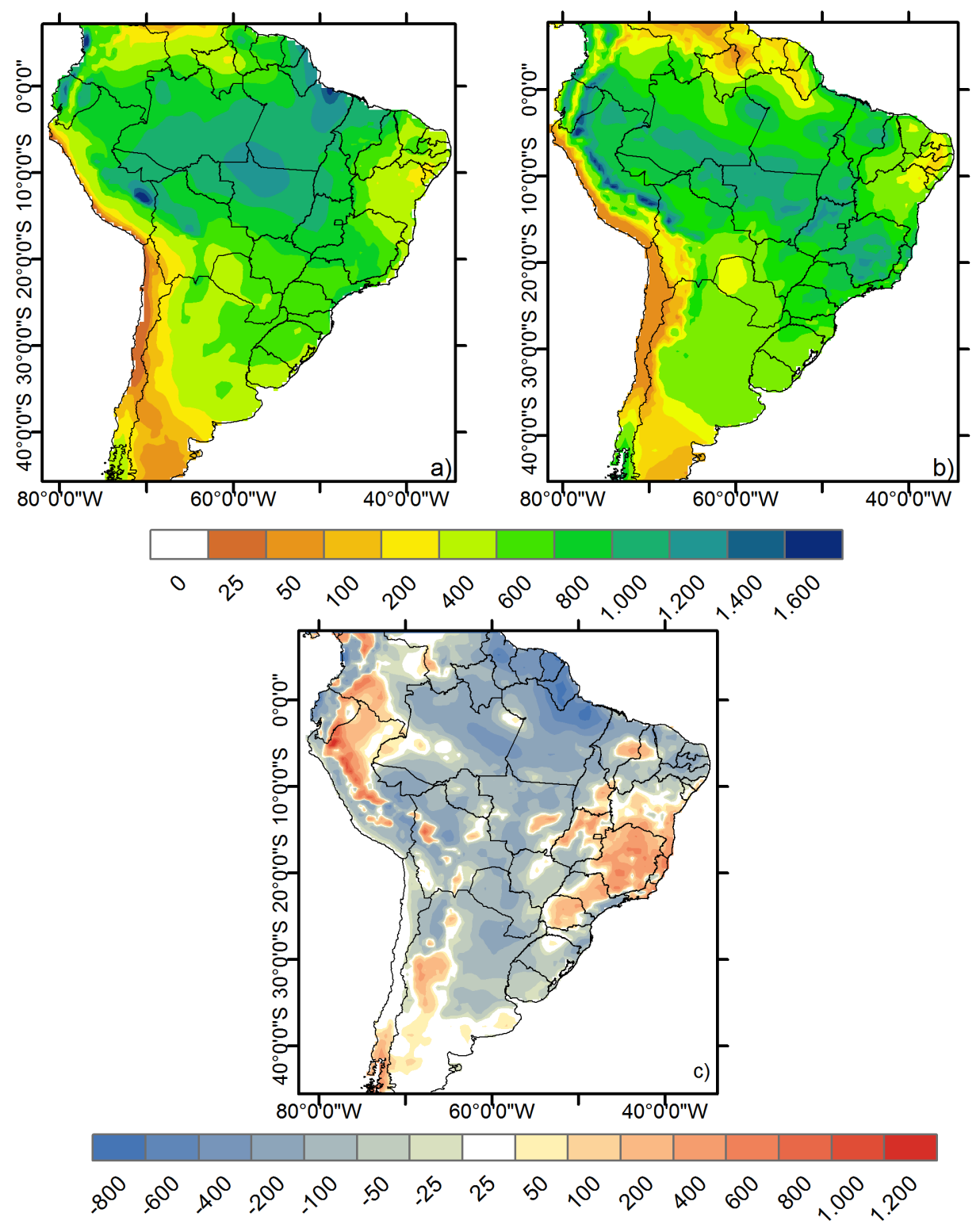

Figure 2. Climatology of accumulated precipitation values relative to the months of JFM from CRU data (a) and ETA model (b); The BIAS between ETA model and CRU data is presented in panel (c). The period of the results are relative to 19811990. Units are in $\mathrm{mm} / \mathrm{month}$. 
To assess anomalies in accumulated rainfall and their percent contributions associated with extreme events for the period 2041-2050, individual types of extremes were quantified and examined. The accumulated rainfall anomalies related to heavy events were negative over a broad region at low latitudes, as can be seen from Figure 3(a). This region covers the Amazon basin and the northeast region of Brazil, with the exception of the western part of the Amazonas State. On the other hand, parts of southeast and southern Brazil and Argentina were characterized by positive anomalies in accumulated rainfall. Since the results suggest that the accumulated rainfall related to heavy events will decrease in the 2041-2050 decade over the Amazon basin and northeast Brazil, it is expected that their percent contribution to the total accumulated rainfall will decrease too. However, this is not the case in northern Brazil (Pará, Maranhão and Tocantins States) where the percent contribution of heavy events increases (Figure 3(b)). The percent contributions were calculated considering the total amount of rainfall accumulated over the considered area and are related to both extreme and non-extreme events. Contrast this with the anomalies presented in Figure 3(a), which were calculated taking into account the total rainfall associated with this specific kind of event and the number of events. If there is a change (increase or decrease) in the total amount of rainfall attributed to extreme events, it is to be expected that the percent contribution of at least one kind of extreme event will also change, although it does not necessarily require that a change will occur in the average extreme event since it can be compensated through a change in the number of extreme events.

When the type (or intensity) of an extreme rainfall event changes, a new spatial behavior of the accumulated rainfall and its percent contribution to the total rainfall is noticed. According to Figure 4(a), the accumulated rainfall anomalies for 2041-2050 are related to very heavy events, positive anomalies in accumulated rainfall in
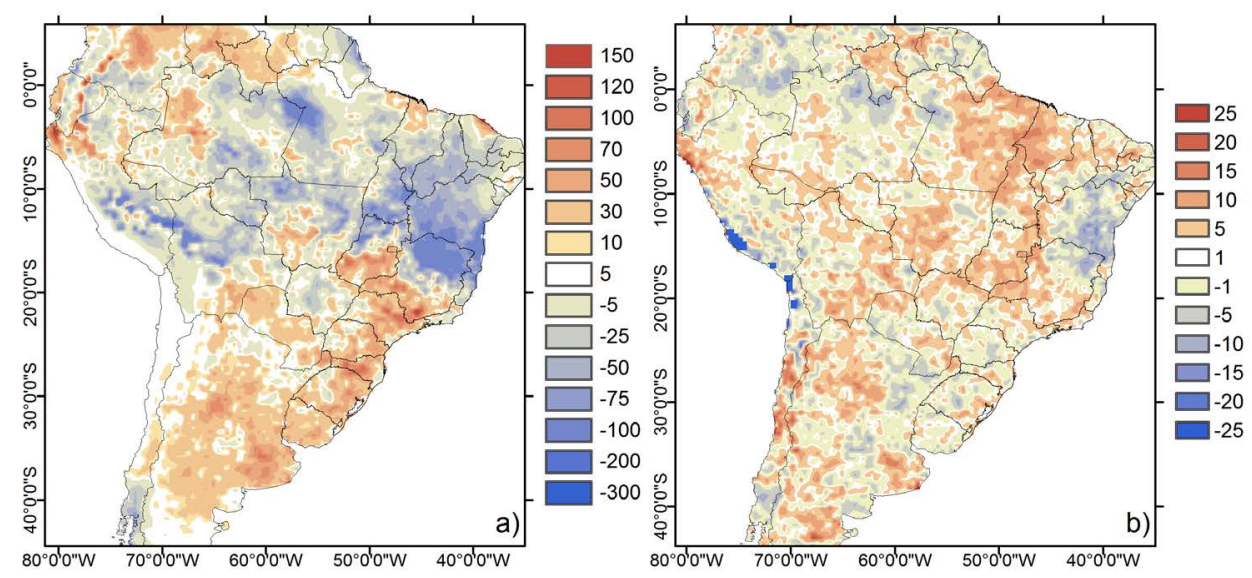

Figure 3. Accumulated rainfall anomalies for JFM related to the heavy events (a) and for percentage contribution to the total rainfall (b). The results are relative to the period of 2041-2050.
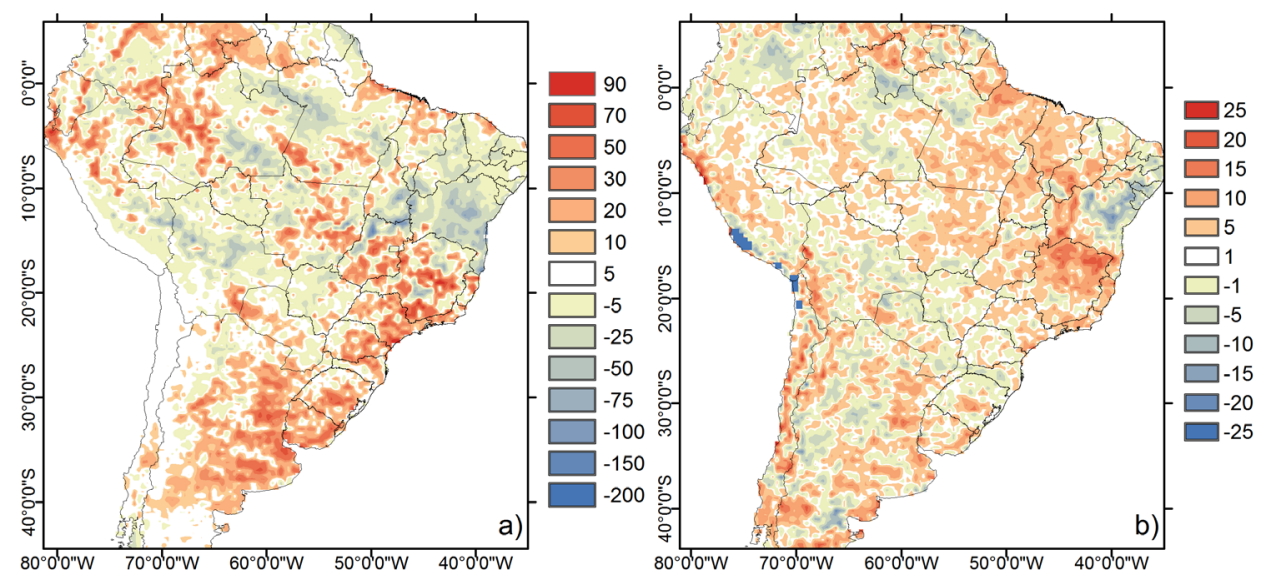

Figure 4. Same as Figure 3, however for very heavy events. 
the western part of Amazonas State, southern Pará and over southeast and southern Brazil. Conversely, negative anomalies are noted over most parts of northeast Brazil, northern Pará and eastern Amazonas State. Moreover, small areas of positive anomalies associated with very heavy events, when compared to heavy events, are present in Argentina. Furthermore, excluding Pará, Maranhão and Tocantíns States, the contribution of very heavy events to the total rainfall increases as the number of accumulated rainfall anomalies increases (Figure 4(b)).

The most extreme intense rainfall was found to produce the largest numbers of rainfall anomalies over most of SA (see Figure 5). According to this graphic, positive anomaly in accumulated rainfall produced by rare events will occur over large parts of the Amazon basin, Pará, Mato Grosso, and southern Brazil and Argentina in the decade 2041-2050. In contrast, negative anomalies in accumulated rainfall are observed over northern Pará State and in northeast Brazil. In the case of rare events, their contribution to rainfall relative to the total rainfall increases over the Amazon basin and the region of northeast Brazil. As can be seen, in the Amazon basin, for example, the most intense rainfall extremes tends to increase, while the weakest events tending to produce less rainfall. In addition, all types of extreme rainfall decrease over northeast Brazil.

To quantify the mean accumulated rainfall by grid point that occurs in specific areas and the associated percentage reduction/increase we present Figures 6-9. Figure 6(a) and Figure 6(b) show the mean accumulated rainfall by grid point occurring just over Amazonas State in the distinct periods of 1981-1990 and 2041-2050, as well as the percentages associated with changes. The total reduction in rainfall over Amazonas State, including non-extreme and extreme rainfall events related to both periods, is seen in Figure 6(a). Moreover, as can be seen from Figure 6(b), the accumulated rainfall related to the rarest kind of extreme rainfall is increased by $12 \%$ over Amazonas State, while normal events, heavy events and very heavy events, respectively, experience decreases of $5 \%, 11 \%$ and $9 \%$. These results reveal that under a scenario of reduced normal events, the accumulated rainfall related to rare events is expected to increase in the middle of the century. The reason for the increase of $12 \%$ in rare events is twofold, i.e., either rare events will be stronger or their relative frequency by grid point will be augmented. In this particular case the average frequency for these events (see Figure 6(c) for absolute values and Figure 6(d) for differences in percentages compared to 1981-1990 decade) presents increase for normal events (1\%, regarding the decrease in accumulated rainfall) and for rare events (4\%). Both heavy and very heavy events frequency agreed with the previous parameter (accumulated rainfall) and decreased $14 \%$ and $12 \%$ respectively.

The mean accumulated rainfall by grid point for the Amazon basin in the periods 1981-1990 and 2041-2050 is presented in Figure 7(a) and Figure 7(b) and values for average frequency in Figure 7(c) and Figure 7(d). From a qualitative point of view, the results for the Amazon basin are similar to those for Amazonas State, i.e., it is expected that under a condition of warming climate normal events, heavy events and very heavy events are expected to diminish, while rare events increase (Figure 7(b)). Similar behavior is observed for frequency (Figure 7(d)). The rate of reduction in accumulated rainfall (frequency) for normal events reaches 18\% (1\%), while heavy events and very heavy events present reductions of $14 \%(9 \%)$ and $11 \%(10 \%)$, respectively. Rare
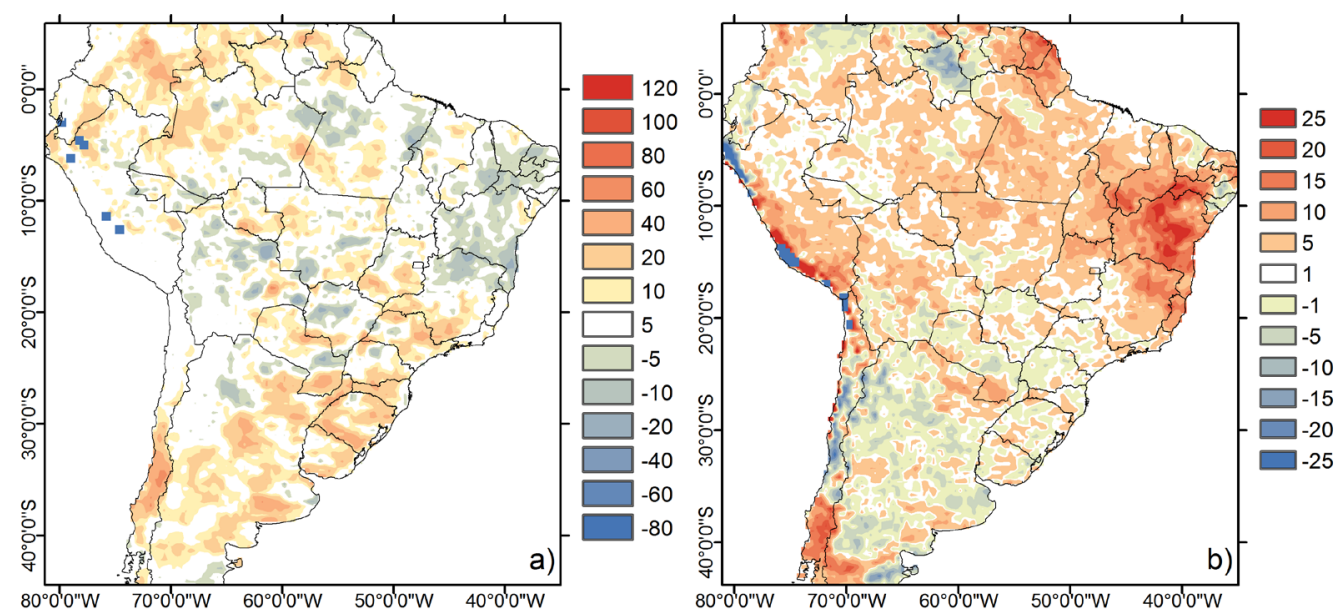

Figure 5. Same as Figure 3, however for rare events. 

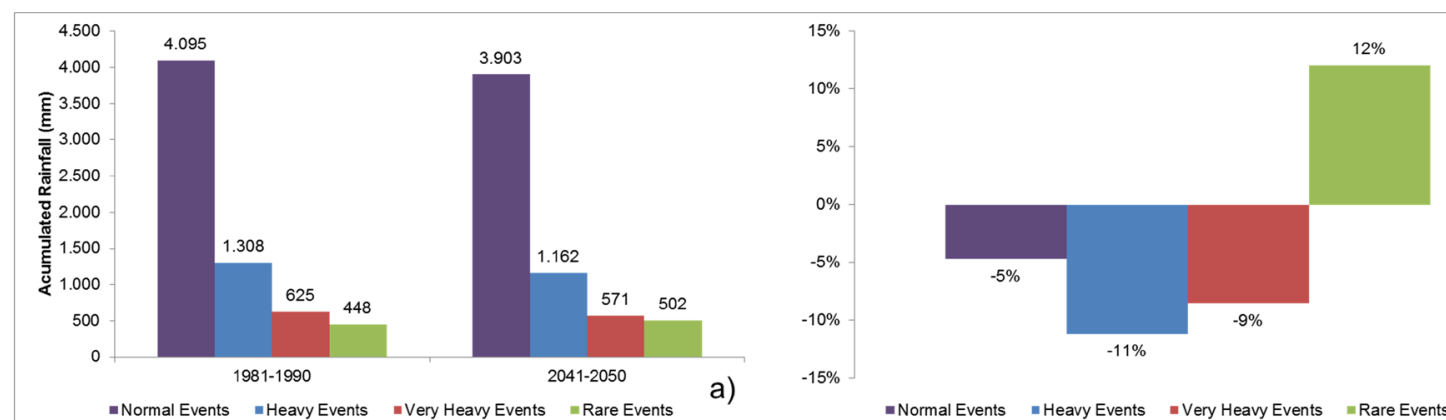

b)
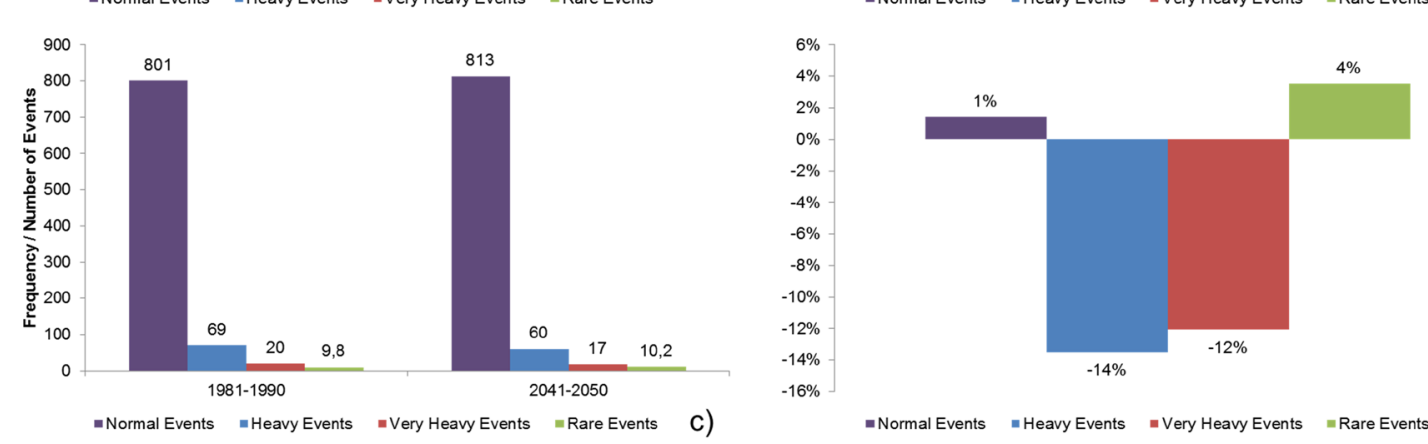

d)

Figure 6. Mean accumulated rainfall by grid points over the Amazonas State (a) percentage difference between mean accumulated rainfall by grid points for 2041-2050 and 1981-1990 (b); c) Mean accumulates frequency by grid point; d) percentage difference between frequency for 2041-2050 and 1981-1990. Purple, blue, red and green color bars denote, respectively, for normal events, heavy events, very heavy events and rare events.
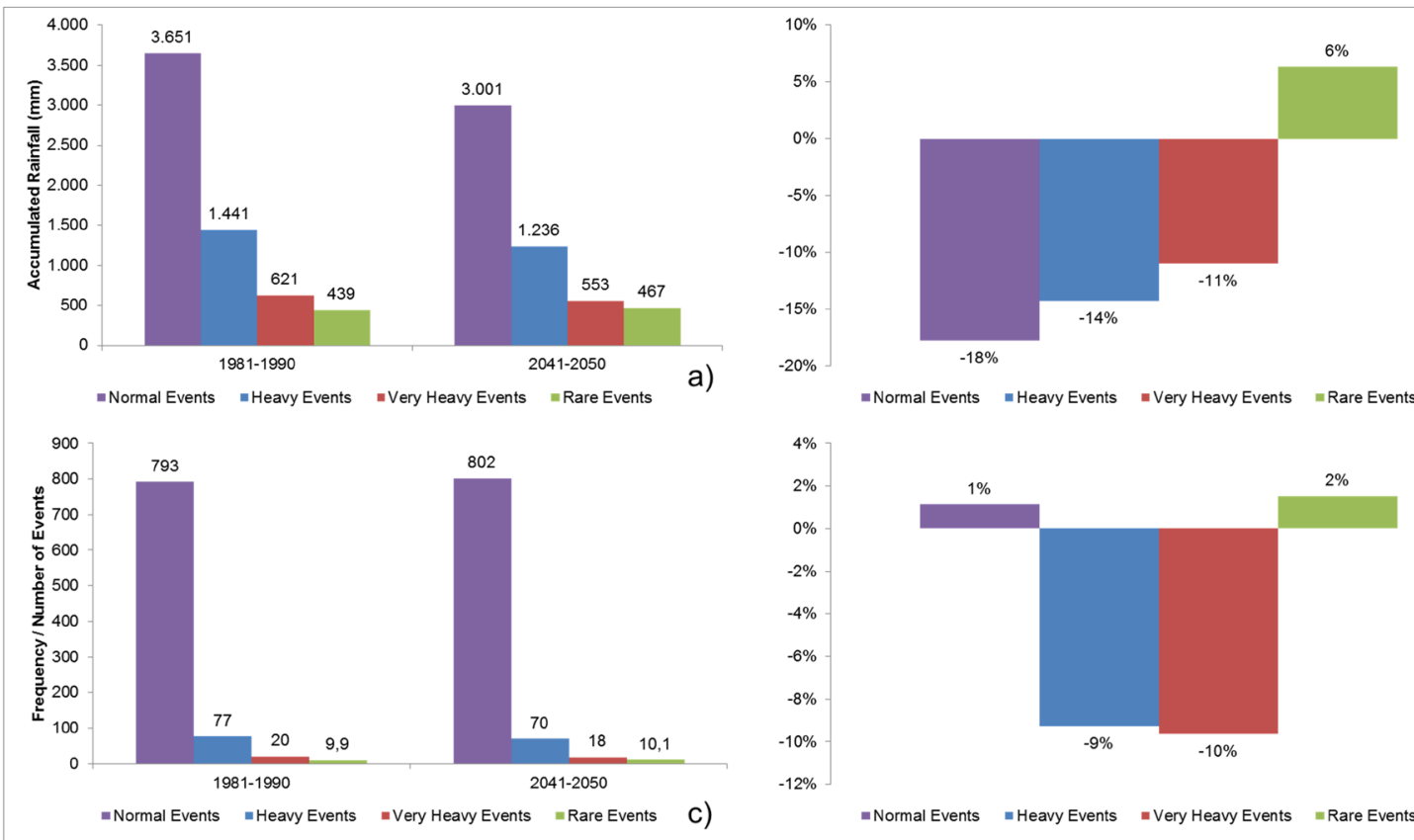

b)

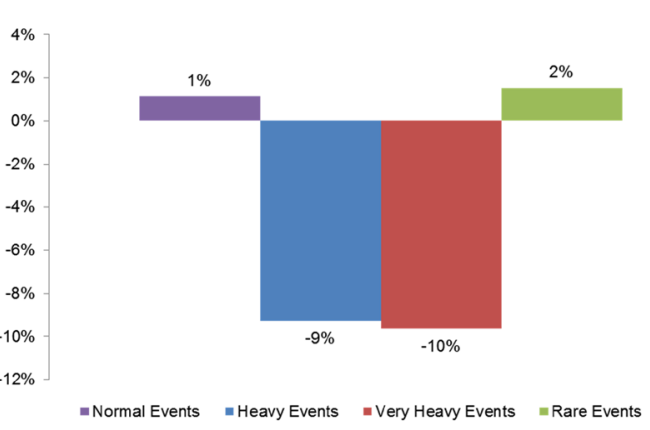

d)

Figure 7. Same as Figure 6, however for Brazilian Amazon.

events increase over the Amazon basin by $6 \%$ for accumulated rainfall and $2 \%$ in frequency. These results suggest that total rainfall over this domain is expected to decline, while the total rainfall related to the rarest events is expected to increase. 
A decrease in the rainfall associated with normal events followed by decreases in heavy, very heavy and rare events is anticipated over the northeast region of Brazil. As can be observed from Figure 8(a) and Figure 8(b), the amount of rainfall related to normal events in 2041-2050 corresponds to just $60 \%$ of what it was in 19811990 (Figure 8(a) and Figure 8(b)). A similar reduction of 36\% is found in heavy events, 35\% in very heavy events and 9\% in rare events. From Figure 8(c) and Figure 8(d) it can be observed that the average frequency increases by $3 \%$ and $1 \%$ for light and rare events while decreasing for the other two kinds of events, by $19 \%$ for heavy events and $23 \%$ for very heavy events. These results suggest that in the near future, considering the increase in GEE emissions, there will be less rainfall over this region whether it is associated with normal or heavy events. The increase in average frequency for normal events and rare events might be due to redistribution between the total number of events, since they were not just diminished in numbers but the total amount of rainfall associated with each kind of extreme event is also reduced.

The last area considered is Southern Brazil, which comprises the Rio Grande do Sul, Santa Catarina and Paraná States. As can be seen in Figure 9(a) and Figure 9(b), there is an increase of 29\% in the total amount of rainfall associated with light events. This increase can also be observed across heavy, very heavy and rare events, increasing by $16 \%, 15 \%$ and $14 \%$, respectively. This tendency is not noted in the average frequency shown in Figure 9(c) and Figure 9(d). For normal events there is a slight increase of 0.3\%, accompanied by reductions in heavy events (1\%), very heavy events (3\%) and rare events (4\%). Although an increase in the average frequency is also expected, its reduction can be explained: there are increases over the mean rainfall per event for each kind of event (light to rare event). In other words, the events are diminishing in frequency but are becoming more intense; as a result, more rainfall is associated with each one, which explains the increase over the total mean rainfall accumulated (Figure 9(b)).

\section{Final Remarks}

Based on a limited area model, we have presented regional changes in extreme rainfall events for the near future 2041-2050 over a broad area in South America. Here, extreme rainfall events are categorized as heavy events, very heavy events and rare events. All these types of events can pose significant threats to human life, and each categorization is based on geographical climatology with no predefined limits.

It was found that all kinds of extremes will undergo significant changes in the near future (2041-2050) with

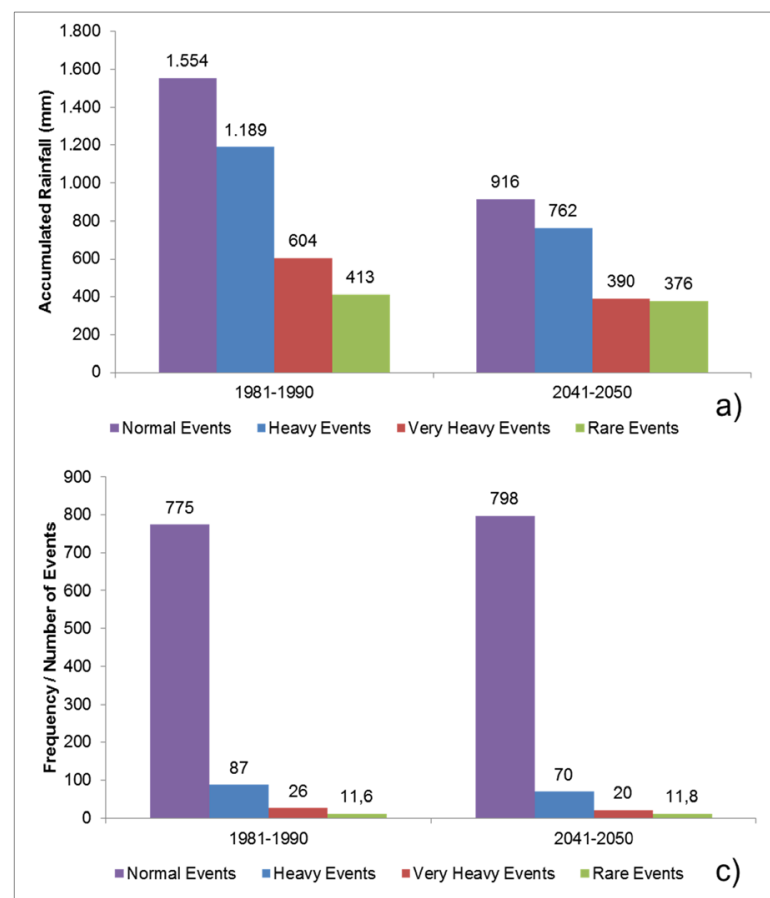

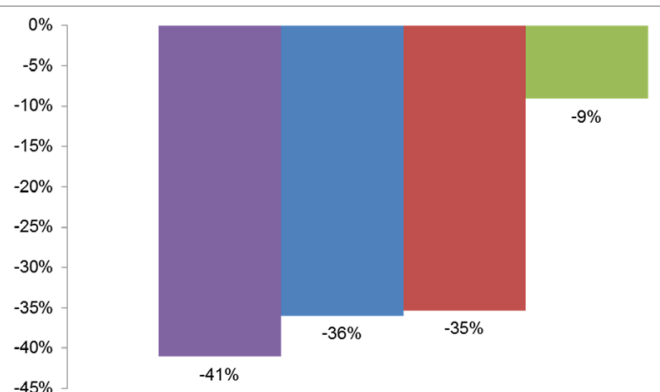

"Normal Events = Heavy Events $\quad$-Very Heavy Events $\quad$ =Rare Events

b)

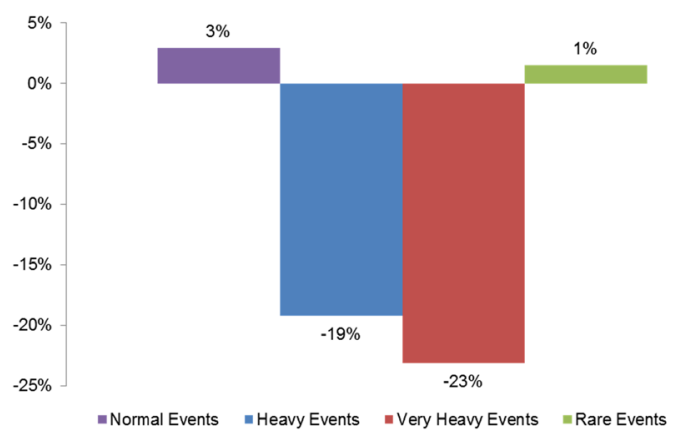

d)

\footnotetext{
Figure 8. Same as Figure 6, however for the northeast region of Brazil.
} 

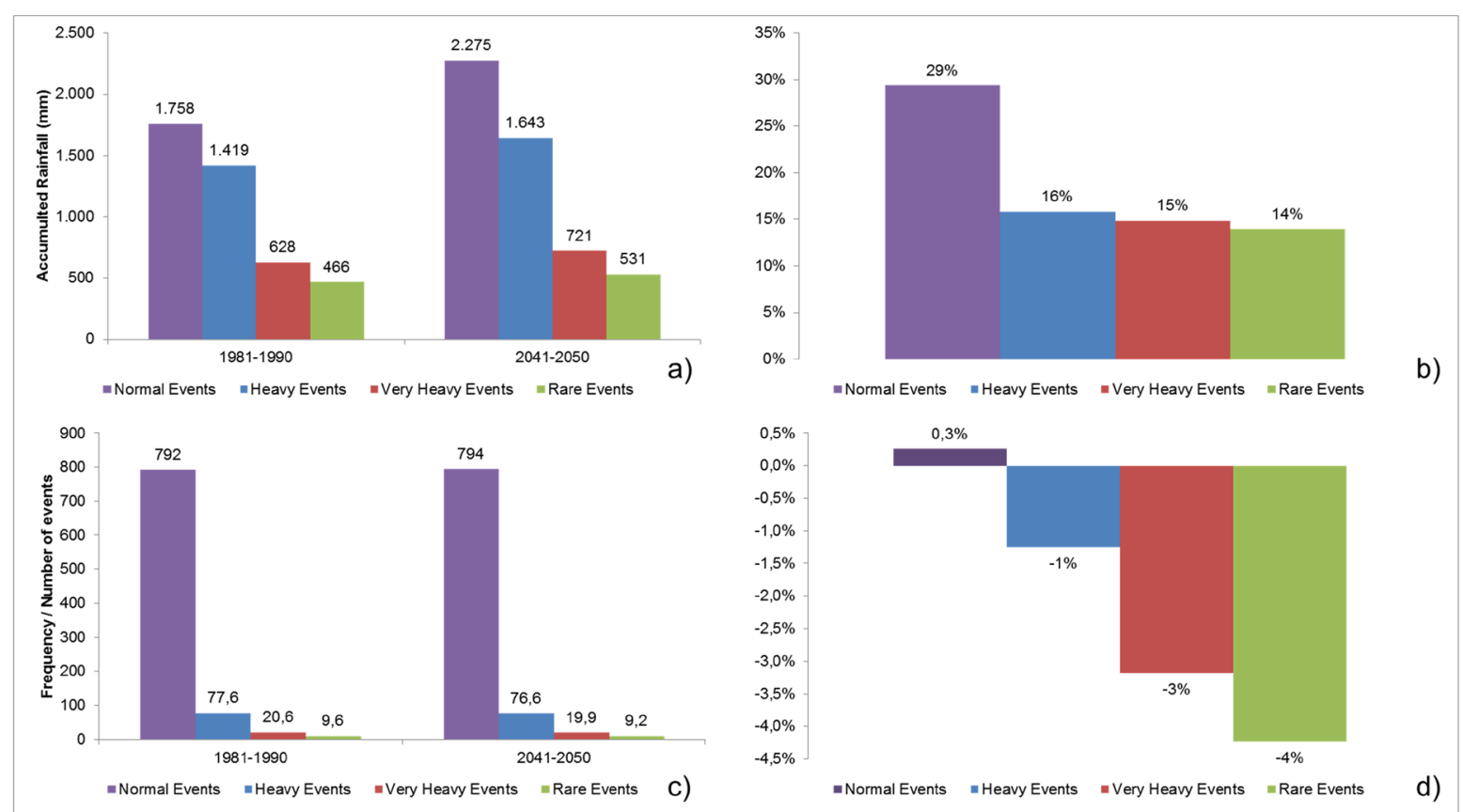

Figure 9. Same as Figure 6, however for the southern of Brazil.

the exact nature of the change depending on the kind of extreme event. Changes in one type can be more dramatic than for another. For example, a spatial analysis revealed that accumulated rainfall provoked by heavy events will be drastically reduced over a broad east-west oriented area over the tropical region. Such an area covers the Amazon basin and northeastern Brazil. Conversely, more rainfall is expected in southern Brazil, Uruguay, Paraguay and Argentina. Both very heavy and rare events are expected to increase in these regions. Over the Amazon basin the accumulated rainfall related to heavy events gradually increases, while it decreases in northern Brazil (spatial analysis).

Quantification of mean accumulated rainfall by grid point over four specific regions of Brazil revealed important characteristics of the extremes. For instance, the total accumulated rain over the Amazonas State domain is reduced, including heavy and very heavy events. However, the accumulated rainfall related to rare events increases by $12 \%$. The results for the Amazon basin domain are similar to the Amazonas State; however, the impact percentage differs. A decrease is expected in rainfall associated with normal events followed by decreases in heavy, very heavy and rare events over northeast Brazil. The results show reductions of 36\%, 35\% and 9\%, respectively, for heavy, very heavy and rare events. The last area considered is southern Brazil, which comprises the Rio Grande do Sul, Santa Catarina and Paraná State; increases were found in heavy, very heavy and rare events, by $16 \%, 15 \%$ and $14 \%$, respectively. This tendency was not observed in the case of frequency. For example, normal events increased slightly $(0.3 \%)$ and heavy events were reduced by $1 \%$, followed by reductions in very heavy events (3\%) and rare events (4\%).

Although the results presented here are only based on one model and probably do not represent a unique picture of extreme rainfalls' future behavior, they still suggest important changes in their contributions to the accumulated rainfall under a warm climate scenario. These results can motivate further investigation based on other limited area climate models.

\section{References}

[1] Allen, M.R. and Ingram, W.J. (2002) Constraints on Future Changes in Climate and the Hydrologic Cycle. Nature, 419, 224-232. http://dx.doi.org/10.1038/nature01092

[2] Trenberth, K.E., Dai, A., Rasmussen, R.M. and Parsons, D.B. (2003) The Changing Character of Precipitation. Bulletin of the American Meteorological Society, 84, 1205-1217. http://dx.doi.org/10.1175/BAMS-84-9-1205

[3] Hennessy, K.J., Gregory, J.M. and Mitchell, J.F.B. (1997) Changes in Daily Precipitation under Enhanced Greenhouse 
Conditions. Climate Dynamics, 13, 667-680. http://dx.doi.org/10.1007/s003820050189

[4] Gordon, H.B., Whetton, P.H., Pittock, A.B., Fowler, A.M. and Haylock, M.R. (1992) Simulated Changes in Daily Rainfall Intensity Due to the Enhanced Greenhouse Effect: Implications for Extreme Rainfall Events. Climate Dynamics, 8, 83-102. http://dx.doi.org/10.1007/BF00209165

[5] Meehl, A.G., et al. (2000) Trends in Extreme Weather and Climate Events: Issues Related to Modeling Extremes in Projections of Future Climate Change. Bulletin of the American Meteorological Society, 81, 427-436. http://dx.doi.org/10.1175/1520-0477(2000)081<0427:TIEWAC>2.3.CO;2

[6] Semenov, V.A. and Bengtsson, L. (2002) Secular Trends in Daily Precipitation Characteristics: Greenhouse Gas Simulation with a Coupled AOGCM. Climate Dynamic, 19, 123-140. http://dx.doi.org/10.1007/s00382-001-0218-4

[7] Allan, R.P. and Soden, B.J. (2008) Atmospheric Warming and the Amplification of Precipitation Extremes. Sciences, 321, 1481-1484. http://dx.doi.org/10.1126/science.1160787

[8] Trenberth, K.E., Fasullo, J. and Smith, L. (2005) Trends and Variability in Column-Integrated Atmospheric Water Vapor. Climate Dynamic, 24, 741-758. http://dx.doi.org/10.1007/s00382-005-0017-4

[9] Marengo, J.A., Nobre, C.A. and Tomasella, J. (2008) The Drought of Amazon in 2005. Journal of Climate, 21, 495516. http://dx.doi.org/10.1175/2007JCLI1600.1

[10] Valipour, M. (2014) Land Use Policy and Agricultural Water Management of the Previous Half of Century in Africa. Applied Water Science. http://dx.doi.org/10.1007/s13201-014-0199-1

[11] Valipour, M., Ahmadi, M.Z., Raeini-Sarjaz, M., Sefidkouhi, M.A.G., Shahnazari, A., Fazlola, R. and Darzi-Naftchali, A. (2014) Agricultural Water Management in the World during Past Half Century. Archives of Agronomy and Soil Science. http://dx.doi.org/10.1080/03650340.2014.944903

[12] Valipour, M. (2012) Critical Areas of Iran for Agriculture Water Management According to the Annual Rainfall. European Journal of Scientific Research, 84, 600-608.

[13] Valipour, M. (2012) Number of Required Observation Data for Rainfall Forecasting According to the Climate Conditions. American Journal of Scientific Research, 74, 79-86.

[14] Marengo, J.A., Borma, L.S., Rodriguez, D.A., Pinho, P., Soares, W.R. and Alves, L.M. (2013) Recent Extremes of Drought and Flooding in Amazonia: Vulnerabilities and Human Adaptation. American Journal of Climate Change, 2, 87-96. http://dx.doi.org/10.4236/ajcc.2013.22009

[15] Marengo, J.A., Javier, T., Alves, L.M., Soares, W.R. and Rodriguez, D.A. (2011) The Drought of 2010 in the Context of Historical Droughts in the Amazon Region. Geophysical Research Letters, 38, L12703. http://dx.doi.org/10.1029/2011GL047436

[16] Marengo, J.A., Tomasella, J., Soares, W.R., Alves, L.M. and Nobre, C.A. (2012) Extreme Climate Events in the Amazon Basin. Theoretical and Applied Climatology, 107, 73-85. http://dx.doi.org/10.1007/s00704-011-0465-1

[17] Espinoza, J.C., Ronchail, J., Frappart, F., Lavado, W., Santini, W. and Guyot, J.L. (2012) The Major Floods in the Amazonas River and Tributaries (Western Amazon Basin) during the 1970-2012 Period: A Focus on the 2012 Flood. Journal of Hydrometeorology, 14, 1000-1008. http://dx.doi.org/10.1175/JHM-D-12-0100.1

[18] Satyamurty, P., da Costa, C.P., Manzi, A.O. and Candido, L.A. (2013) A Quick Look at the 2012 Record Flood in the Amazon Basin. Geophysical Research Letters, 40, 1396-1401. http://dx.doi.org/10.1002/grl.50245

[19] Fearnside, P.M. (2014) As barragens e as inundações no rio Madeira. Ciência Hoje, 53, 53-57.

[20] Fearnside, P.M. (2014) Impacts of Brazil’s Madeira River Dams: Unlearned Lessons for Hydroelectric Development in Amazonia. Environmental Science and Policy, 38, 164-172. http://dx.doi.org/10.1016/j.envsci.2013.11.004

[21] Satyamurty, P., de Castro, A.A., Tota, J., da Silva Gularte, L.E. and Manzi, A.O. (2010) Rainfall Trends in the Brazilian Amazon Basin in the Past Eight Decades. Theoretical and Applied Climatology, 99, 139-148. http://dx.doi.org/10.1007/s00704-009-0133-x

[22] Correia, F.W.S., Alvalá, R.C.S. and Manzi, A.O. (2007) Modeling the Impacts of Land Cover Change in Amazônia: A Regional Climate Model (RCM) Simulation Study. Theoretical and Applied Climatology, 93, 225-244.

[23] Sud, Y.C., Chao, W. and Walker, G. (1993) Dependence of Rainfall on Vegetation: Theoretical Considerations, Simulation Experiments, Observations, and Inferences from Simulated Atmospheric Soundings. Journal of Arid Environments, 25, 5-18. http://dx.doi.org/10.1006/jare.1993.1038

[24] Sampaio, G., Nobre, C., Costa, M.H., Satyamurty, P., Soares-Filho, B.S. and Cardoso, M. (2007) Regional Climate Change over Eastern Amazônia Caused by Pasture and Soybean Cropland Expansion. Geophysical Research Letters, 34, LI7709.

[25] Chen, T.C., Takle, J.H. and Yoon, K.J. (2003) Impacts on South America Rainfall Due to Changes in Global Circulation. Proceedings of the 7th International Conference on Southern Hemisphere Meteorology and Oceanography, American Meteorological Society, Boston, 92-93. 
[26] Valverde, M. and Marengo, J.A. (2011) Rainfall Extremes Events Climatology over the Amazon Basin. Proceedings of the Global Conference on Global Warming, Lisbon, 11-14 July 2011, 1-8.

[27] Marengo, J.A., Nobre, C.A., Chou, S.C., et al. (2011) Riscos das Mudanças Climáticas no Brasil. Análise Conjunta Brasil-Reino Unido Sobre os Impactos das Mudanças Climáticas e do Desmatamento na Amazônia, 2-56.

[28] Carvalho, L.M., Jones, C. and Liebmann, B. (2003) The South Atlantic Convergence Zone: Intensity, Form, Persistence, and Relationships with Intraseasonal to Interannual Activity and Extreme Rainfall. Journal of Climate, 17, 88-108. http://dx.doi.org/10.1175/1520-0442(2004)017<0088:TSACZI >2.0.CO;2

[29] Valipour, M. (2014) Future of the Area Equipped for Irrigation. Archives of Agronomy and Soil Science, 60, 16411660 .

[30] Wheater, H. and Evans, E. (2009) Land Use, Water Management and Future Flood Risk. Land Use Policy, 26, S251-S264. http://dx.doi.org/10.1016/j.landusepol.2009.08.019

[31] Valipour, M. (2014) Future of Agricultural Water Management in Americas. Journal of Agricultural Research, 2, 245-267.

[32] Chou, S.C., Marengo, J.A., Lyra, A.A., Sueiro, G., Pesquero, J.F., Alves, L.M., et al. (2011) Downscaling of South America Present Climate Driven by 4-Member HadCM 3 Runs. Climate Dynamics, 38, 635-653.

[33] Collins, M., Tett, F.S.B. and Cooper, C. (2001) The Internal Climate Variability of HadCM3, a Version of the Hadley Centre Coupled Model without Flux Adjustments. Journal of Climate, 17, 61-81.

[34] Gordon, C., Cooper, C., Senior, C.A., Banks, H., Gregory, J.M., Johns, T.C., Mitchell, J.F.B. and Wood, R.A. (2000) The Simulation of SST, Sea Ice Extents and Ocean Heat Transports in a Version of the Hadley Centre Coupled Model without Flux Adjustments. Journal of Climate, 16, 147-168.

[35] Pope, V.D., Gallani, M.L., Rowntree, P.R. and Stratton, R.A. (2000) The Impact of the New Physical Parametrizations in the Hadley Centre Climate Model: HadAM3. Climate Dynamics, 16, 123-146. http://dx.doi.org/10.1007/s003820050009

[36] Nakicenovic, N., Alcamo, J., Davis, G., et al. (2000) Special Report on Emissions Scenarios, Intergovernmental Panel on Climate Change. Cambridge University Press, Cambridge, United Kingdom and New York, 599 p.

[37] Black, T.L. (1994) The New NMC Mesoscale ETA Model: Description and Forecast Examples. Weather and Forecasting, 9, 265-278. http://dx.doi.org/10.1175/1520-0434(1994)009<0265:TNNMEM>2.0.CO;2

[38] Janjié, Z. (1994) The Step-Mountain Eta Coordinate Model: Further Developments of the Convection, Viscous Sublayer, and Turbulance Closure Schemes. Monthly Weather Review, 122, 927-945. http://dx.doi.org/10.1175/1520-0493(1994)122<0927:TSMECM>2.0.CO;2

[39] Zhao, Q., Black, T.L. and Baldwin, M.E. (1997) Implementation of the Cloud Prediction Scheme in the Eta Model at NCEP. Weather and Forecasting, 12, 697-712. http://dx.doi.org/10.1175/1520-0434(1997)012<0697:IOTCPS>2.0.CO;2

[40] Chen, F., Janjié, Z. and Mitchell, K. (1997) Impact of Atmospheric Surface-Layer Parameterizations in the New LandSurface Scheme of the NCEP Mesoscale Eta Model. Boundary-Layer Meteorology, 85, 391-421. http://dx.doi.org/10.1023/A:1000531001463

[41] Ek, M.B., Mitchell, K.E., Lin, Y., Rogers, E., Grunmann, P., Koren, V., Gayno, G. and Tarpley, J.D. (2003) Implementation of NOAH Land Surface Advances in the National Centers for Environmental Prediction Operational Mesoscale Eta Model. Journal of Geophysical Research, 108, 8851.

[42] Sestini, M.F., dos Santos Alvalá, R.C.D., Mello, E.L.K., de Morisson Valeriano, D., Chan, C.S., Nobre, C.A., et al. (2002) Elaboração de mapas de vegetação para utilização em modelos meteorológicos e hidrológicos. INPE, São José dos Campos, 64 p.

[43] Lacis, A.A. and Hansen, J. (1974) A Parameterization of the Absorption of Solar Radiation in Earth’s Atmosphere. Journal of the Atmospheric Sciences, 31, 118-133. http://dx.doi.org/10.1175/1520-0469(1974)031<0118:APFTAO>2.0.CO;2

[44] Fels, S.B. and Schwarzkopf, M.D. (1975) The Simplified Exchange Approximation: A New Method for Radiative Transfer Calculations. Journal of the Atmospheric Sciences, 32, 1475-1488. http://dx.doi.org/10.1175/1520-0469(1975)032<1475:TSEAAN>2.0.CO;2

[45] Frich, P., Alexander, L.V., Della-Marta, P., Gleason, B., Haylock, M., Klein Tank, A.M.G. and Peterson, T. (2002) Observed Coherent Changes in Climatic Extremes during the Second Half of the Twentieth Century. Climate Research, 19, 193-212. http://dx.doi.org/10.3354/cr019193

[46] Gao, X., Pal, J.S. and Giorgi, F. (2006) Projected Changes in Mean and Extreme Precipitation over the Mediterranean Region from a High Resolution Double Nested RCM Simulation. Geophysical Research Letters, 33, L03706. http://dx.doi.org/10.1029/2005GL024954 
[47] Tank, A.M.G.K., Zwiers, F.W. and Zhang, X., Eds., World Meteorological Organization (2009) Guidelines on Analysis of Extremes in a Changing Climate in Support of Informed Decisions for Adaptation. Climate Data and Monitoring WCDMP-No. 72, Switzerland, 52 p.

[48] Brito, A.L., Veiga, J.A.P. and Yoshida, M.C. (2014) Extreme Rainfall Events over the Amazon Basin Produce Significant Quantities of Rain Relative to the Rainfall Climatology. Atmospheric and Climate Sciences, 4, 179-191. http://dx.doi.org/10.4236/acs.2014.42021

[49] Goswami, B.N., Venugopal, V., Sengupta, D., Madhusoodanan, M.S. and Xavier, P.K. (2006) Increasing Trend of Extreme Rain Events over India in a Warming Environment. Science, 314, 1442-1445.

http://dx.doi.org/10.1126/science.1132027 
Scientific Research Publishing (SCIRP) is one of the largest Open Access journal publishers. It is currently publishing more than 200 open access, online, peer-reviewed journals covering a wide range of academic disciplines. SCIRP serves the worldwide academic communities and contributes to the progress and application of science with its publication.

Other selected journals from SCIRP are listed as below. Submit your manuscript to us via either submit@scirp.org or Online Submission Portal.
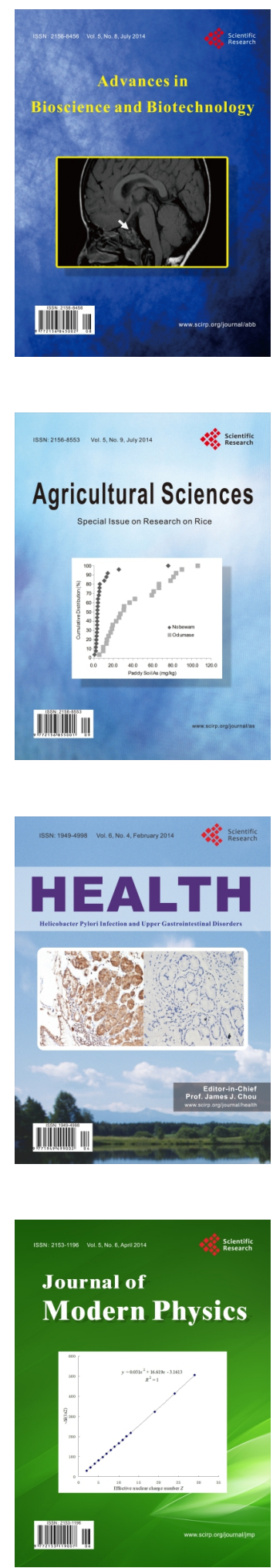
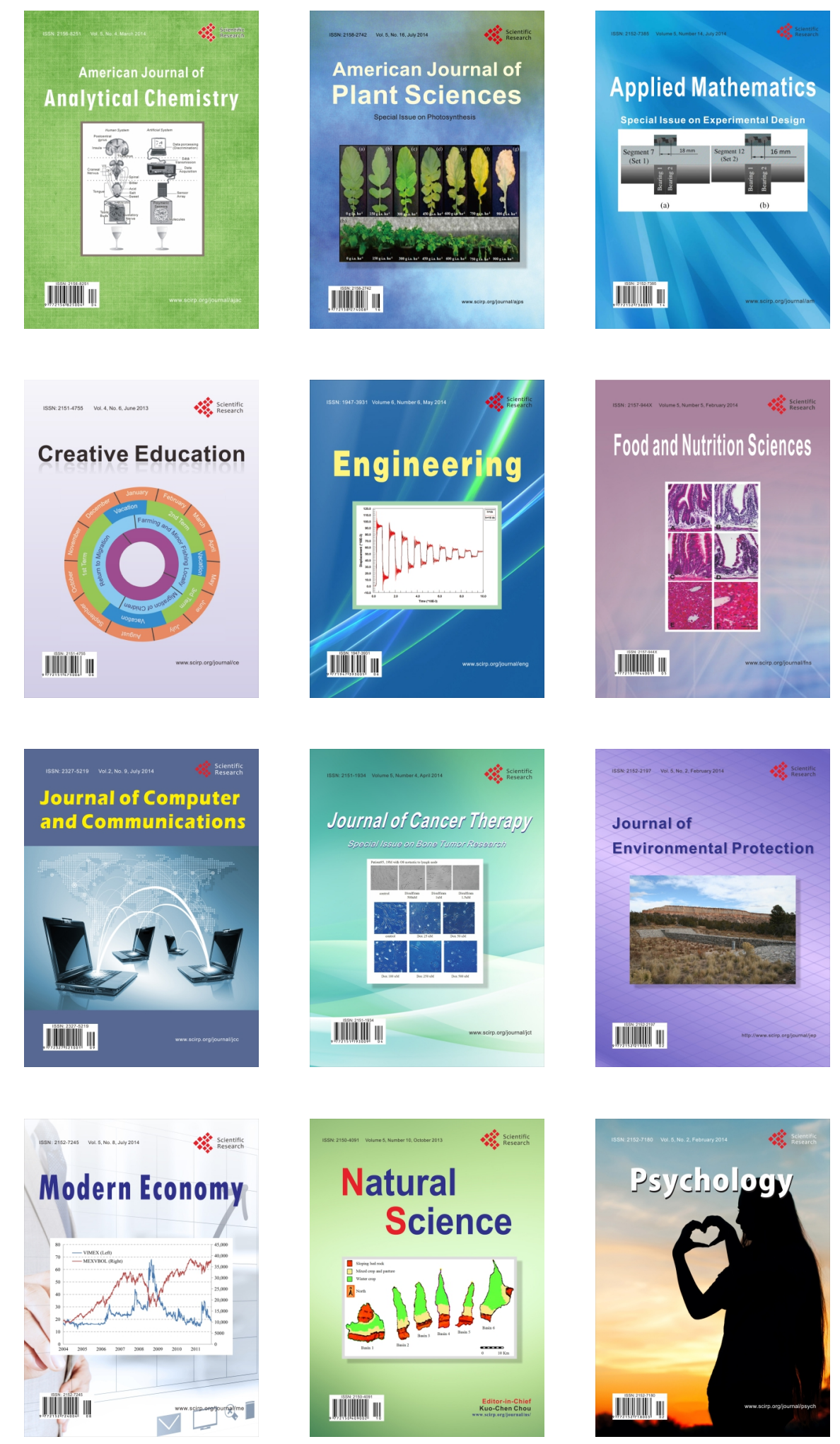